\title{
Teorias de jornalismo para gêneros jornalísticos
}

\author{
Lia Seixas
}

Resumo: Este artigo traz as primeiras considerações teóricas de uma pesquisa sobre metodologia de gêneros jornalísticos. O objetivo é observar até onde categorias como "finalidade", "propósito", lead e enfoque operam e como noções capitais para os estudos do jornalismo (atualidade, instantaneidade, periodicidade, valor-notícia, fato, acontecimento) podem operar na análise dos gêneros jornalísticos. Durante cinco dias pelo método da "semana construída", analisamos os principais destaques das homes de dois sites noticiosos de referência: elpais. com e oglobo.globo.com. As primeiras considerações são: 1) a noção de instantaneidade revela a importância das noções de fato e acontecimento para a compreensão de gêneros jornalísticos; 2) finalidade é uma noção de dimensão sociocultural associada à noção de "função do jornalismo", determinada pelas noções de formato e estrutura ("sequências"); 3) periodicidade é a noção da ordem do produto, outro elemento que deve fazer parte dos estudos de gêneros jornalísticos; 4) a noção de enfoque não opera; e 5) a lógica do chamado texto informativo não é necessariamente de sequências expositivas e/ou explicativas como se afirma e reafirma nos estudos de gêneros jornalísticos, podendo ter, ao contrário, domínio das sequências argumentativas e de variadas sequências.

Palavras-chave: gêneros jornalísticos; teorias do jornalismo; sites noticiosos

Abstract: Theories of journalism for journalistic genres - This article discusses the first theoretical considerations of a research on the methodology of journalistic genres. The goal is to observe to what extent categories such as "finality," "purpose," lead and approach operate and how capital notions for journalism studies (currency, instantaneity, periodicity, news value, fact, event) can work in the analysis of journalistic genres. For five days, by means of the "constructed week" method, we analyzed the main news items on the home pages of two reference news sites: elpais.com and oglobo.globo.com. The first considerations are: 1) the notion of instantaneity reveals the importance of the notions of fact and event in understanding journalistic genres; 2) finality is a notion of sociocultural dimension associated with the notion of "function of journalism," which is determined by notions of format and structure ("sequences"); 3) periodicity is the notion of the order of the product, another element that should be part of studies on journalistic genres; 4) the notion of approach does not work; and 5) the logic of the so-called informational text is not necessarily of expository and/or explanatory sequences, as has been stated and restated in studies of journalistic genres, but may, instead, fall within the domain of argumentation sequences and of varied sequences.

Keywords: journalistic genres; theories of journalism; news websites 


\section{O "jornalístico" dos gêneros jornalísticos}

Onde estão as teorias do jornalismo nos estudos de gêneros jornalísticos? Que noções compõem a fundamentação dos estudos de textos, composições discursivas, "formatos" (como se queira chamar as notícias, reportagens, artigos, entrevistas) produzidos por organizações jornalísticas? O que é próprio do adjetivo "jornalístico" nas análises de gêneros de jornais impressos, revistas impressas, programas radiofônicos, televisivos, sites noticiosos? Muito pouco.

Herdeiros da retórica, da teoria da literatura, da linguística, da análise do discurso, dos estudos culturais, os estudos de gêneros jornalísticos em impresso, rádio e televisão no Brasil, na verdade, têm mantido, ao fundo, apenas noções como enfoque, lead; mais tangencialmente, acontecimento e fato; e, de maneira mais abrangente, as noções de contrato fiduciário e valor-notícia. Enfoque e lead aparecem na definição de "formatos" (LAILTON, 2010) como cronologia ou "história colorida". Assim como os termos fato e acontecimento aparecem mal definidos na explicação de nota, notícia, reportagem, uma consequência da frágil definição desses conceitos nos próprios estudos de jornalismo. Na análise de gêneros televisivos, contrato fiduciário e valor-notícia fundamentam a compreensão da instituição jornalística com o nascimento do jornalismo moderno.

Certamente, a noção de gênero jornalístico diz respeito ao texto, ao discurso, à narratividade, se quisermos. Categorias como função e finalidade, tratadas também como propósito ou intencionalidade, narração, dissertação e "relato" são importantes. Entretanto, ao mesmo tempo que são frequentemente questionadas na geração de classificações dentro da comunicação e dos campos de origem, não são tensionadas com noções e categorias das teorias do jornalismo, que pensam a instituição, a lógica do fazer-jornalístico, seu processo produtivo, suas propriedades. Na linguística, por exemplo, o conceito de "propósito comunicativo" tem sido interrogado por ser variado para cada gênero e na relação com o interlocutor, além da sua dimensão subjetiva. A compreensão da estrutura textual já avançou da narração e da dissertação para noções como "sequência" (ADAM, 1992).

Com o objetivo de observar até onde nos levam categorias como "finalidade", "propósito", lead e enfoque, e analisar se e como noções capitais para os estudos do jornalismo (atualidade, instantaneidade, periodicidade, valor-notícia, fato, acontecimento) podem operar na análise de gêneros jornalísticos, fizemos uma pesquisa com produtos webjornalísticos, geralmente não contemplados nos estudos de gêneros jornalísticos do Brasil e, quando contemplados, analisados segundo características das mídias digitais ${ }^{1}$.

1 Esta pesquisa faz parte do projeto do Laboratório de Jornalismo Convergente, financiado pela Fundação de Amparo à Pesquisa do Estado da Bahia (Fapesb), do qual a autora é vice-coordenadora. Participou desta pesquisa a estudante de jornalismo Joana Oliveira, bolsista Pibic-UFBA 


\section{Metodologia e corpus}

O principal elemento que fundamenta as classificações de gêneros no Brasil é a função/finalidade (MARQUES DE MELO, 1985; 2010). A finalidade é a base das teorias da linguagem e da sociologia. Ainda que já tenhamos considerado a finalidade mais uma dimensão da instituição social jornalística (SCHUDSON, 2008) do que de uma composição discursiva (SEIXAS, 2009), incluímo-la na pesquisa para amadurecer essa compreensão e, principalmente, para tentar compreender como essa categoria pode fundamentar a noção de gênero jornalístico. Assim, comparou-se a finalidade (informativa, opinativa, interpretativa - visa explicar -, utilitária - visa prestar serviço - e diversional - visa entreter, proposta ao que seria o "jornalismo literário" (MARQUES DE MELO)) com a "função da linguagem" de Roman Jakobson (1995), pois são consideradas "fatores constitutivos de todo processo linguístico, de todo ato de comunicação verbal" (JAKOBSON, 1995, p. 129): remetente, destinatário, mensagem, contexto, contato e código. Ou seja, fatores dos quais se originam as condições de êxito dos atos de fala (AUSTIN, 1990), dos atos linguísticos (MAINGUENEAU, 2002), condições que colocam o ato de comunicação e a enunciação em primeiro plano.

Outra noção influente na definição de gênero jornalístico é a de enfoque. Um exemplo representativo é a definição de "história de interesse humano", gênero diversional (conhecido no Brasil como "jornalismo literário") na compreensão do grupo de Marques de Melo:

\footnotetext{
Narrativa que privilegia facetas particulares dos "agentes" noticiosos. Recorrendo a artifícios literários, emergem dimensões inusitadas de protagonistas anônimos ou traços que humanizam os "olimpianos". Apesar da apropriação de recursos ficcionais, os relatos devem primar pela "verossimilhança" sob o risco de perder a "credibilidade". Destina-se a preencher os espaços ociosos dos aficionados por relatos jornalísticos (COSTA, 2010, p. 75).
}

O enfoque dá conta da abertura do texto (ECO, 1984), ou seja, precisa considerar, em primeiro lugar, que há uma estrutura textual, o que muitas composições digitais não possuem (ex.: galeria de imagem). Ao mesmo tempo, a estrutura tem sido estudada no seu sentido macro, considerando o domínio da narração para determinados gêneros e dissertação para outros. Sabe-se, entretanto, que as estruturas de composições discursivas jornalísticas são muito variadas, inclusive com o surgimento de novos formatos em novas plataformas. Por isso, introduzimos a categoria de análise "sequência" de Michel Adam (1992). As sequências são esquemas, blocos de proposições que fazem parte da estrutura composicional dos textos, mas não são macroestruturais. Um texto argumentativo pode conter diversas sequências, entre as quais narrativa, descritiva, dialogal, explicativa/expositiva, além da argumentativa. As sequências atravessariam os gêneros e seriam menos variáveis do que: 
A diferença fundamental da sequência em relação ao gênero, como já foi dito antes, é sua menor variabilidade. Os gêneros marcam situações sociais específicas, sendo essencialmente heterogêneos. Já as sequências, como componentes que atravessam todos os gêneros, são relativamente estáveis, logo, mais facilmente delimitáveis em um pequeno conjunto de tipos (uma tipologia) [...] (BONINI, 2005, p. 218).

As sequências podem ajudar a explicar a finalidade através do formato, já que a estrutura representa culturalmente um posicionamento da "autoria". Acredita-se que o chamado texto informativo, considerado clássico do texto jornalístico, tem mais sequências argumentativas e explicativas do que normalmente se considera, pois, muitas vezes, o lead traz uma síntese que viria no texto argumentativo clássico, como o artigo, no final. É necessário destacar ainda que se trabalhou com as características das sequências de Adam (1992), mas não se considerou todo o esquema prototípico, quer dizer, não se considerou que uma sequência deveria conter todas as características descritas para ser uma sequência. A sequência narrativa pode conter: 1) sucessão de eventos; 2) unidade temática; 3) processo, ou seja, início, meio e fim; 4) intriga, conjunto de causas que dá sustentação aos fatos; 5) moral, reflexão sobre o fato narrado. A sequência argumentativa tem três partes: dados, escoramento de inferências e conclusão. A sequência descritiva deve conter aspectualização e/ou estabelecimento de relação. A sequência explicativa apresenta três partes: levantar questionamento, responder questionamento ou resolver problemas, detalhando-o, e sumarizar resposta. Por último, a sequência dialogal é formada pelas fáticas (que testam o canal, ritualísticas) e pela transacional (compõe o corpo da interação) (BONINI, 2005).

Algumas sequências são mais autônomas do que outras, como a descritiva, que não tem ordem tão fixa como a narrativa e a argumentativa, o que, para nós, significa a possibilidade de testar características das sequências sem que se precise de todas elas para validar a operação lógica, cognitiva. Algumas sequências se associam ainda às perguntas do lead (originárias da retórica de Quintiliano), por exemplo, a resposta à questão "como?" para a sequência descritiva ou "onde e quando?" para a sequência narrativa ou ainda "por quê?" para a sequência argumentativa. A lógica do texto característico da instituição social jornalística, chamado texto informativo, inclui, para nós, muitas sequências "expositivas", que, embora consideradas por Adam como explicativas, estão em análise, já que acreditamos que muitas proposições informativas não seriam nem descritivas nem explicativas como poderia reinterpretar Adam.

A instantaneidade é categoria fundamental, uma vez que as teorias do jornalismo consideram o jornalismo uma forma de conhecimento sobre a realidade atual (MEDITSCH, 1997). A instantaneidade, mais do que característica de mídias como a radiofônica, a televisiva e a digital, é parte do conceito de atualidade, uma das propriedades do jornalismo (GROTH, 2011; BELTRÃO, 1960; FRANCISCATO, 2005). Instantaneidade é o lapso de tempo entre o momento da ocorrência e a sua publicação no produto jornalístico. 
Através da observação da instantaneidade, é possível conhecer melhor a matéria-prima do jornalismo, comumente considerada como fatos e/ou acontecimentos. O "tempo de validade" da realidade noticiada interfere no tempo da composição discursiva, no gênero jornalístico. A instantaneidade é de alguma forma também elemento da tipologia de Gaye Tuchman, pois trabalha com a relação entre o tipo de ocorrência/evento e a rotina que a ocorrência demanda: hard news (acontecimento inesperado), spot news, developing news (acontecimento em desenvolvimento), continuing news (acontecimento em continuação), acontecimento predeterminado (TUCHMAN, 1980).

Essa tipologia dialoga ainda com os critérios de noticiabilidade, pois trata exatamente de tipos de notícia (news). Os dois elementos da análise de Tuchman são: 1) alguns valores-notícia como inesperado, extraordinário e interesse público; e 2) a instantaneidade. Sendo assim, fez-se também uma análise dos valores-notícias, ou seja, dos critérios substantivos relativos às ocorrências: grau e nível hierárquico das pessoas, impacto sobre a nação e o interesse nacional, proximidade (cultural, geográfica), quantidade de pessoas envolvidas, relevância (consequências), morte, novidade, notabilidade (qualidade de ser tangível), inesperado, conflito e controvérsia, infração.

Elencamos ainda periodicidade, por considerarmos, como Otto Groth, que se trata de uma propriedade do jornalismo. Mais do que apenas uma marca do período, da constância e do hábito, a identidade do produto (GROTH, 2011). Mesmo um site noticioso, determinado pela atualização contínua, portanto, sem periodicidade no sentido da constância, é dotado da periodicidade identidade, por que: 1) pode ter diferentes periodicidades para diferentes composições, seções e produtos como blogs ou infográficos; e 2) a continuidade da atualização é sua identidade de "site noticioso", diferentemente de um especial, de uma revista eletrônica, de um blog. O próprio adjetivo "noticioso" fortalece o conceito de notícia, da hard news.

Conhecidas as categorias, explicamos as decisões metodológicas para análise quantitativa e qualitativa. Cada composição foi analisada segundo todas as categorias elencadas e depois fez-se uma comparação quantitativa e qualitativa duas ou três categorias em função de hipóteses e/ou objetivos. Selecionamos os principais destaques das homes de elpais.com e oglobo.globo.com, dois sites de referência (quality papers) no Brasil e na Espanha. Estabelecemos a semana construída (SOUSA, 2004) e os principais destaques da home a fim de garantir: 1) a maior variedade possível de composições; e 2) o critério da importância estabelecido pelo site noticioso ao levar a composição para a home.

Assim, foram analisadas 83 composições de home-pages dos dois sites. Examinamos destaques em média do elpais.com (totalizando 48) e sete destaques em cada dia do oglobo.globo.com (totalizando 35). Entre 20 e 22 h², dos dias 11 e 19 de abril (quarta

2 O intervalo das 19 às 23 h está dentro do horário nobre da internet para sites jornalísticos, conforme conversas informais recentes com coordenadores de sites noticiosos baianos e de site noticioso do Grupo Folha da Manhã. 
e quinta, respectivamente), 4, 7 e 15 de maio (sexta, segunda e terça, respectivamente), foram selecionados os principais destaques por blocos.

Cada home tem três colunas e na primeira tela (primeira rolagem) aparecem comumente hard news (mais frequentemente na coluna da esquerda ou às vezes horizontalmente em três colunas, no caso do elpais.com, quando se trata de manchete) e blocos de editorias, seções, recursos automáticos. Em oglobo.globo.com, dia tem notícia principal, composição de "Blogs e colunistas", bloco com fio, "Seleção O Globo", "Direto da Redação", "Eu repórter" e o primeiro comentário de "+ comentadas, + enviadas". Em elpais.com, notícia principal (manchete do momento), notícia de destaque na coluna do meio, principais destaques dos blocos "Desportes", "Última hora" (Eskup), "Cultura y Televisón", "Blogs", "Entrevista digital", "Opinión", "El Viajero", "Especiales", "Vídeos" e algumas de "Fotografía".
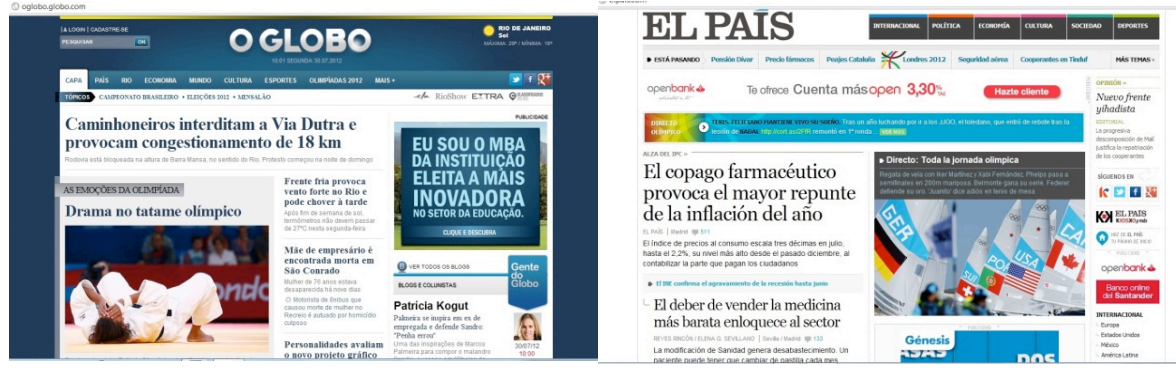

Fig.1. Home-pages com três colunas, em 30/7/12, às 10 h16.

A metodologia privilegiou três principais tensionamentos: 1) finalidade, função da linguagem e sequência, para observar se as funções da linguagem e as sequências seguiriam a finalidade, por acreditarmos que as composições discursivas de produtos jornalísticos podem apresentar mais de duas funções da linguagem e diversas sequências; $2^{\circ}$ ) finalidade, evento/ocorrência e instantaneidade, com o objetivo de observar se os chamados gêneros informativos teriam como matéria-prima ocorrências (acontecimentos) e os gêneros opinativos teriam como matéria-prima "acontecimentos jornalísticos" produzidos pela organização jornalística e testar a classificação de Gay Tuchman, baseada em regimes temporais e valores-notícia (inesperado, imprevisível); $3^{\circ}$ ) enfoque e sequências, por acreditarmos que enfoque não é determinante na mudança de gênero, como reportagens de editorias de cultura que abrem com personagens, cenas ou eventos históricos, mas sim, as sequências, pela estrutura do texto, podem levar à compreensão de outra finalidade.

\section{Primeiras considerações teóricas}

A instantaneidade, relação temporal entre ocorrência e publicação, é considerada elemento componente da lógica do jornalismo. Parte-se do pressuposto que as composições 
do gênero informativo (como notícia e reportagem) têm como matéria-prima sempre uma ocorrência. Para 90\% das composições consideradas de finalidade informativa, esse pressuposto se confirma. Dado que traz de volta um dos dois principais critérios de classificação de Marques de Melo (1985): o que chamou de "natureza estrutural dos relatos observáveis nos processos jornalísticos".

[...] Tomamos em consideração a articulação que existe do ponto de vista processual entre os acontecimentos (real), sua expressão jornalística (relato) e a apreensão pela coletividade (leitura). É por isso que visualizamos diferenças entre a natureza e diferenças entre os gêneros que se incluem na categoria informativa e dos que compõem a categoria opinativa. Os gêneros que correspondem ao universo da informação se estruturam a partir de um referencial exterior à instituição jornalística: sua expressão depende diretamente da eclosão e evolução dos acontecimentos e da relação que os mediadores profissionais (jornalistas) estabelecem em relação aos seus protagonistas (personalidades ou organizações). Já no caso dos gêneros que se agrupam na área de opinião, a estrutura da mensagem é codeterminada por variáveis controladas pela instituição jornalística e que assumem duas feições: autoria (quem emite a opinião) e angulagem (perspectiva temporal ou espacial que dá sentido à opinião) (MARQUES DE MELO, 1985, p. 64) (grifo nosso).

Portanto, na maior parte das vezes, a matéria-prima do gênero informativo é marcada pelo lapso de tempo entre realização e publicação. Além disso, 100 \% das manchetes analisadas (10 composições) têm até um dia de instantaneidade, das quais $60 \%$ (ou seja, seis) são de acontecimento inesperado (hard news), com interesse público e relevância inquestionáveis. Ou seja, eventos que eclodem dotados de valores-notícias geram, na maior parte das vezes, gêneros com finalidade informativa.

Mas há de se notar (ver quadro 1) que em 22 ( composições = soma de informativa com outros objetos, exceto eventos) cuja principal finalidade é a informativa, não se pode considerar a relação entre realização e publicação, porque não há evento/ocorrência, trata-se de situação (algo em processo), tema (sem temporalidade), evento futuro ou outro produto (diversas composições). Duas conclusões: a primeira e mais óbvia, embora não discutida nas teorias do jornalismo, é que a matéria-prima do jornalismo, inclusive dos gêneros informativos, não é composta só de fatos, mas também de eventos em processo e objetos como pessoas, produtos culturais e cidades; a segunda é que a publicação de composições com finalidade informativa não depende necessariamente da eclosão e evolução de acontecimentos, a não ser que se considere uma situação um "acontecimento jornalístico". A situação, entretanto, revela outro fenômeno considerado por Grothparte da atualidade, a simultaneidade. A situação está ocorrendo ao mesmo tempo que é discurso jornalístico. 


\begin{tabular}{|l|l|}
\hline $\begin{array}{l}\text { FINALIDADE DO OBJETO } \\
\text { (oglobo.globo.com + elpais.com) }\end{array}$ & $\begin{array}{l}\mathbf{8 3} \\
\text { composições* }\end{array}$ \\
\hline Informativa com evento/ocorrência $(14+28=42)$ & $50,6 \%$ \\
\hline Opinativa como situação $(8+3=11)$ & $13,2 \%$ \\
\hline Opinativa com tema $(3+4=7)$ & $8,4 \%$ \\
\hline Informativa com situação $(4+0=4)$ & $4,8 \%$ \\
\hline Opinativa com produto $(0+4=4)$ & $4,8 \%$ \\
\hline Informativa com produto $(0+3=3)$ & $3,6 \%$ \\
\hline Informativa com tema $(0+2=2)$ & $2,4 \%$ \\
\hline Informativa com evento futuro $(0+2=2)$ & $2,4 \%$ \\
\hline Utilitária com cidade $(0+2=2)$ & $2,4 \%$ \\
\hline Dialógica com tema $(0+2=2)$ & $2,4 \%$ \\
\hline Opinativa com evento/ocorrência $(1+0=1)$ & $1,2 \%$ \\
\hline Informativa com comportamento $(1+0=1)$ & $1,2 \%$ \\
\hline FINALIDADE E INSTANTANEIDADE & $\mathbf{8 3}$ composições \\
\hline Informativa com até $\mathbf{1}$ dia (destas, $\mathbf{1 0 0} \%$ das manchetes) $(\mathbf{1 0}+\mathbf{2 5}=\mathbf{3 4 )}$ & $40,9 \%$ \\
\hline Informativa sem marca de temporalidade $(\mathbf{6}+\mathbf{5}=\mathbf{1 1})$ & $20,3 \%$ \\
\hline Opinativa sem marca de temporalidade $(\mathbf{1 0}+\mathbf{7}=\mathbf{1 7})$ & $74 \%$ \\
\hline
\end{tabular}

*A percentagem da segunda comparação não se fecha porque são alguns elementos comparados, enquanto $2,8 \%$ da primeira comparação se refere a Especiais, outro produto jornalístico não analisado, mas linkado no site noticioso.

Quadro 1. Comparativo finalidade/evento/instantaneidade

Por outro lado, embora 74 das composições cuja principal finalidade é opinativa não estejam sob o regime da instantaneidade, no site noticioso é representativa uma composição com ocorrência de até um dia em relação à publicação: "França: porta aberta para conciliar corte e crescimento" (blog de Míriam Leitão, O Globo, 07/05/12). A composição do blog, com formato que indica fortemente a finalidade opinativa (nomenclatura com assinatura de um sujeito-autor), trata de ocorrência do mesmo dia, reação do mercado financeiro com eleições presidenciais na Grécia e na França. Certamente que a estrutura é dominada pela sequência argumentativa, mas a matéria-prima é a queda nas bolsas de valores. Se para essa composição houve algum planejamento, sabe-se também que 
produtos jornalísticos como impressos ou sites noticiosos planejam todo o tempo suas coberturas, principalmente porque muitos dos eventos são "acontecimentos predeterminados" (nessa amostra, o que equivale a composições).

A instantaneidade, além de ter uma dimensão sociocultural e outra dimensão de materialidade física associada aos processos de transmissão e distribuição da notícia (FRANCISCATO, p. 121), já que é característica da mídia com velocidade da difusão (MCLUHAN), tem também associação direta com a ocorrência da realidade, noção que compõe o conceito, mas que não foi analisada nesses termos. Nesse sentido, a instantaneidade parece influenciar fortemente na composição que se pode produzir sobre um dado evento, um tema ou uma situação; ou melhor, sobre o que se pode cobrir rotineiramente e o que se deve planejar. Consequentemente, a instantaneidade (juntamente com a periodicidade, característica da dimensão do produto), vai conformando gêneros discursivos, pois são os formatos que "dão certo", que se institucionalizam e se estabelecem como gêneros jornalísticos.

A instantaneidade, embora diga respeito ao lapso de tempo entre a ocorrência e sua publicização, focada, portanto, em fatos (ocorrências passadas), também precisa ser analisada na relação com o futuro. Dois exemplos são representativos: 1) destaque sobre o Salão Internacional de Turismo na Catalunha ("Un mercado de felicidade" em "El Viajero", elpais.com, 19/04/12) que se realizaria quatro dias depois; e 2) destaque sobre lançamento de filme dias após a publicação da composição ("'Homens de preto 3' terá viagem no tempo e Josh Brolin no elenco", oglobo.globo.com, 07/05/12). Tanto o lançamento de um produto cultural como um evento são ocorrências corriqueiras e frequentes no conteúdo jornalístico. Não há instantaneidade, certamente porque não ocorreram, mas são acontecimentos predeterminados (TUCHMAN, 1983), pois já agendados, mas do futuro.

É importante dizer que, característica da mídia digital, a instantaneidade permite a produção com atualização contínua, mas isso não significa que todo conteúdo jornalístico deva estar sob o crivo dela. Se a matéria-prima não for evento/ocorrência, não se pode falar em instantaneidade; no máximo, em atualidade. Uma revista semanal, com frequência de sete dias, não pauta ocorrências, exceto se estas se realizam um dia antes da publicação. Muitos sites jornalísticos laboratoriais de faculdades de jornalismo não são caracterizados por hard news. Certamente a mídia permite, tem instantaneidade; mas as condições de produção, segundo tempo de aulas, regime de notas, currículo (quando dentro de disciplina), automóveis e equipamentos, não permitem.

Nesse sentido, condições de produção podem determinar a periodicidade de um produto e, consequentemente, os gêneros que se pode produzir. Nenhuma composição dos 83 destaques analisados mostrou qualquer marca textual capaz de identificar periodicidade, mesmo de seções. No caso de editoriais e artigos, o hábito diz que são publicados a cada dia, como nos impressos. Como o produto é site noticioso, o tempo é multicrônico, a frequência de formatos e caracterização de seções e/ou colunas é livre. A periodicidade, portanto, considerada por muitos autores (GROTH, BELTRÃO) uma propriedade do "jornal" e do jornalismo, é uma característica do produto. Assim como instantaneidade não é apenas característica da mídia, devendo ser analisada segundo a matéria-prima, a periodicidade 
não deixa de existir em função da potencialidade instantânea da mídia, pois depende do produto. Ou seja, outro elemento pouco analisado nos estudos de gêneros jornalísticos é o produto, porque é considerado pressuposto, como no caso do jornal impresso, ou porque é compreendido como gênero televisivo, levando o adjetivo da mídia.

Mas, se as noções de periodicidade, instantaneidade, acontecimento, valor-notícia parecem produtivas para os estudos de gêneros jornalísticos, a noção de enfoque não tem levado a lugar nenhum. A não ser para composições com estrutura clássica argumentativa, ou pequenas estruturas com domínio da expositiva, como legendas de fotos, todas as outras composições dos sites noticiosos observados têm enfoque. Além disso, o enfoque não é capaz de influenciar na finalidade, que seria levar uma composição do gênero informativo para o gênero interpretativo ou diversional. Exemplos representativos são coberturas esportivas. Todas as cinco composições da cobertura do futebol começam com recursos que se denominariam "literários", como metáforas ou comparações entre objetos, personagens, sentimentos. Todas têm o domínio da sequência argumentativa (pois há uma tese que domina o texto), embora tenham sequências explicativas, descritivas e narrativas; no entanto, todas têm a finalidade informativa, não só pela matéria-prima (jogo de futebol), mas também pelo formato. Mesmo composições sobre eventos que não são jogos, mas são eventos de HQ (Salón del Comic de Barcelona), por mais que o enfoque seja a comparação entre as potências econômicas e o "mundo do cômico" da China em relação ao Japão, com estrutura dominada pela sequência argumentativa, a finalidade continua sendo informativa. A lógica do chamado texto informativo, portanto, não é necessariamente de sequências expositivas (24\%) ou explicativas $(4,8 \%)$, mas pode ser de domínio das sequências argumentativas (10,8 \%) e de variadas sequências (20,4\%).

\begin{tabular}{|l|l|l|}
\hline ENFOQUE com SEQUÊNCIAS & $\mathbf{8 3}$ composições & De composições \\
\hline Tem enfoque com domínio da expositiva & 20 & $24 \%$ \\
\hline Tem enfoque e variadas sequências & 17 & $20,4 \%$ \\
\hline Não tem enfoque e tem domínio da argumentativa & 16 & $19,2 \%$ \\
\hline $\begin{array}{l}\text { Tem enfoque e tem domínio da argumentativa (coberturas } \\
\text { esportivas, composições de blogs, aquelas de finalidade } \\
\text { utilitária e da editoria de cultura e política) }\end{array}$ & 9 & $10,8 \%$ \\
\hline $\begin{array}{l}\text { Não tem enfoque e tem domínio da expositiva (composi- } \\
\text { ções de Eskup e legendas de fotos em elpais.com) }\end{array}$ & 7 & $8,4 \%$ \\
\hline \begin{tabular}{l} 
Tem enfoque e tem domínio da explicativa \\
\hline Não tem enfoque e tem domínio da dialógica
\end{tabular} & 2 & $4,8 \%$ \\
\hline Tem enfoque e tem domínio da narrativa & 1 & $2,4 \%$ \\
\hline
\end{tabular}


Um motivo, acreditamos, é que a finalidade é da ordem do saber social, da cultura, do reconhecimento intersubjetivo. A finalidade não é da ordem da subjetividade, da intencionalidade. Dois elementos são fundamentais no estabelecimento dela: formato e estrutura (sequências ou, com a pragmática, atos linguísticos). Das 83 composições analisadas, 54 têm como principal finalidade informativa; 23, opinativa; quatro, com finalidade utilitária; e duas com finalidade dialógica. Na comparação analítica feita com finalidade, função da linguagem e sequência, alguns dados são relevantes: 1) 100\% das composições com finalidade principal informativa (total de 49 composições) têm como principal função da linguagem a referencial; 2) sete composições têm como principal função da linguagem a referencial e emotiva como secundária - todas no elpais.com, da editorias de esporte ou política, em função das sequências descritivas e argumentativas; 3) as composições da seção "Entrevistas Digitales" começam com função da linguagem apelativa e fática e terminam com função da linguagem emotiva, portanto nascem com finalidade dialógica e são arquivadas, transformando-se em composição opinativa; 4) exceto editoriais e artigos, que possuem estrutura dissertativa clássica com domínio da sequencia argumentativa, todas as outras composições de qualquer finalidade têm sequências muito variadas, pois das 49 composições com finalidade principal informativa, apenas a metade (51) tem estrutura dominada pela sequência expositiva; e 5) das composições com principal finalidade informativa têm formato com título informativo ou subtítulo informativo, foto ou vídeo, legenda e hipertexto (exceção apenas dos "Especiales", que se constituem em outro produto, como outro template).

\begin{tabular}{|l|l|l|}
\hline FINALIDADE COM FUNÇÕES DA LINGUAGEM & $\mathbf{8 3}$ composições & De composições* \\
\hline Informativa com referencial & 49 & $59 \%$ \\
\hline Opinativa com emotiva & 13 & $15,6 \%$ \\
\hline Opinativa com referencial e emotiva (elpais.com) & 7 & $8,4 \%$ \\
\hline Informativa com referencial e emotiva (editoria de esporte) & 7 & $8,4 \%$ \\
\hline Utilitária com referencial e emotiva & 2 & $2,4 \%$ \\
\hline Utilitária com referencial & 2 & $2,4 \%$ \\
\hline Utilitária com referencial e emotiva (elpais.com) & 2 & $2,4 \%$ \\
\hline Dialógica com apelativa e emotiva (“Entrevistas Digitales”) & 2 & $2,4 \%$ \\
\hline Opinativa com emotiva e apelativa & 1 & $1,2 \%$ \\
\hline Opinativa com emotiva e metalinguística & 1 & $1,2 \%$ \\
\hline Informativa com referencial e apelativa & $1,2 \%$ \\
\hline
\end{tabular}




\begin{tabular}{|l|l|l|}
\hline FINALIDADE E SEQUÊNCIA & $\mathbf{8 3}$ composições & De composições \\
\hline Informativa com domínio da sequência expositiva & 25 & $51 \%$ \\
\hline Opinativa com domínio da sequência argumentativa & 14 & $16,8 \%$ \\
\hline Informativa com sequências explicativas a expositivas & 9 & $10,8 \%$ \\
\hline $\begin{array}{l}\text { Informativa com variadas sequências (argumentativa, expo- } \\
\text { sitiva, explicativa, descritiva, narrativa) }\end{array}$ & 9 & 10,85 \\
\hline Informativa com domínio da sequência argumentativa & 7 & $8,4 \%$ \\
\hline Opinativa com variadas sequências & 6 & $7,2 \%$ \\
\hline Opinativa com domínio da sequência explicativa & 4 & $4,8 \%$ \\
\hline Utilitária com domínio da argumentativa e da explicativa & 3 & $3,6 \%$ \\
\hline $\begin{array}{l}\text { “Dialógica” com domínio da sequência dialógica (exem- } \\
\text { plo do “Entrevistas Digitales") }\end{array}$ & 2 & $2,4 \%$ \\
\hline $\begin{array}{l}\text { Informativa com sequência narrativa (obituário em elpais. } \\
\text { com) }\end{array}$ & 1 & $1,2 \%$ \\
\hline $\begin{array}{l}\text { Opinativa com sequência dialógica (exemplo da entrevis- } \\
\text { ta) }\end{array}$ & 1 & $1,2 \%$ \\
\hline \begin{tabular}{l} 
Utilitária com sequência narrativa (exemplo em El Viajero) \\
\hline
\end{tabular} & 1 & $1,2 \%$ \\
\hline
\end{tabular}

*As percentagens não devem somar porque expressam incidência de dois elementos numa mesma composição.

Quadro 3. Comparativo finalidade/funções da linguagem/sequências

Acredita-se que, como nas pesquisas fundamentadas pelos estudos culturais, o que indica a finalidade é o saber social sobre o formato - este último compreendido aqui como produto da cultura que "se reporta tanto à exploração de processamentos cognitivos e tecnológicos quanto à modelização semiótica de códigos, linguagens e sistemas de signos" (MACHADO, 2010, p. 96). No ato comunicativo, primeiro vem o formato, depois a estrutura, as sequências. O formato é algo anterior ao ato de leitura, está no saber social (ISER, 1996), assim como a função da instituição jornalística associada aos produtos. Exemplo produtivo para esta análise é a composição com o título "As 10 telas mais caras já leiloadas". Apresenta-se com título, texto curto de duas linhas e imagens em slideshow, com legenda. O formato é de uma "galeria de imagens", mas o site noticioso o chama de infográfico, o que só é possível notar se o usuário rolar para o bloco abaixo com o termo "Outros infográficos". Não há informação através de desenho e/ou gráfico, apenas pelo texto escrito, pelas legendas. Um motivo talvez seja a inserção no sistema do 
slideshow, formato frequente dos infográficos de oglobo.globo.com. Infográfico ou galeria de imagem pelo usuário, o formato se realiza como informativo. Ao mesmo tempo, há uma associação do formato com a identidade do produto e com as finalidades da instituição social à qual pertence.

As composições com funções da linguagem apelativa (principal) e fática (secundária), que se realizam com finalidade dialógica, são compostas de sequências dialógicas, pergunta-resposta. A finalidade poderia ser pensada, segundo o saber social, como "finalidade de interação", exatamente o que sugerem os estudos do jornalismo digital quando falam em interatividade como propriedade da mídia digital e/ou do jornalismo digital. Se defendermos como gênero diversional, ainda assim as funções da linguagem apelativa e fática entrariam em conflito. Se relacionarmos as funções da linguagem com as funções da instituição social jornalística (information, investigation, analysis, social empathy, public forum, mobilization (SCHUDSON, 2008)), certamente escolheríamos a função de "fórum público". Mas por que, então, não se reconhece uma composição com finalidade de "fórum público" ou "interação" se esta é considerada função da instituição jornalística? Essa relação precisa ser teoricamente feita.

\section{Afinal, onde se chegou}

Ao final, não sabemos ainda como os elementos dos estudos brasileiros de gêneros jornalísticos podem operar analiticamente e que relações devem ser feitas entre estes elementos e aquelas noções das teorias do jornalismo, mas é possível dizer que: 1) instantaneidade, considerada fenômeno da atualidade, é uma das categorias dos estudos de jornalismo que deveriam fazer parte da metodologia de análise de gêneros jornalísticos porque revela a importância das noções de fato e acontecimento para a compreensão de gêneros jornalísticos e ilumina a relação entre objeto e discurso jornalístico; 2) enfoque é uma noção dos estudos do jornalismo que não opera nas definições de gêneros, nem mesmo de "formatos" (como Marques de Melo nomeia as unidades textuais e que chamamos de composições discursivas); 3) categorias decisivas dos estudos de gêneros, como finalidade e "propósito", precisam ser cotejadas com categorias dos estudos de jornalismo, como "funções do jornalismo" - informação, investigação, análise, empatia social, fórum público, mobilização (SCHUDSON, 2008) - e formato (MACHADO, 2010, p.96); 4) categorias pouco exploradas nos estudos de gêneros como fato (GOMES, 2009), "acontecimento jornalístico" (RODRIGUES, 1999), "hard news, soft news, continuing news, developing news" (TUCHMAN, 1980) e, consequentemente, valor-notícia (WOLF; TRAQUINA) revelam a importância de se considerar - como já havia pontuado Marques de Melo em 1985 - a relação entre o real e a estrutura "dos relatos observáveis", ou seja, condições de produção e do discurso na compreensão do gênero jornalístico; e 5) a lógica do chamado texto informativo não é necessariamente de sequências expositivas e/ou 
explicativas como se afirma e reafirma nos estudos de gêneros jornalísticos, podendo ter, ao contrário, domínio das sequências argumentativas e de variadas sequências.

Lia Seixas é professora adjunta da Facom-UFBA e do Programa de Pós-Graduação em Comunicação e Cultura Contemporânea.

liaseixas@gmail.com

\section{Referências:}

ADAM, Jean-Michel. La linguistique textuelle. Introduction à I'analyse textuelle des discours. Paris: Armanda Colin, 2006.

AS 10 TELAS mais caras já leiloadas. In: O Globo, Rio de Janeiro, 4 maio 2012. Disponível em: <http:// oglobo.globo.com/infograficos/ranking-pinturas-leilao/>. Acesso em: set. 2012.

ASSIS, Francisco de; MARQUES DE MELO, José (Org.). Gêneros jornalísticos no Brasil. São Bernardo do Campo: Metodista, 2010.

AUSTIN, John. Quando dizer é fazer. Palavras e ação. Porto Alegre: Artes Médicas, 1990.

BELTRÃO, L. Introdução à filosofia do jornalismo. Rio de Janeiro: Agir Editora, 1960.

BONINI, Adair. A noção de sequência textual na análise pragmático-textual de Jean-Michel Adam. In: MEURER, J. L.; BONINI, A.; MOTTA-ROTH, D. (Org.). Gêneros: teorias, métodos, debates. São Paulo: Parábola Editorial, 2005.

COSTA, Lailton da. Gêneros jornalísticos. In: ASSIS, Francisco de; MARQUES DE MELO, José (Org.). Gêneros jornalísticos no Brasil. São Bernardo do Campo: Metodista, 2010.

ECO, Umberto. Conceito de texto. São Paulo: EDUSP, 1984.

EL CÓMIC chino, el tebeo que arrasa. In: El País, Cultura, 4 maio 2012. Disponível em: <http:// cultura.elpais.com/cultura/2012/05/04/actualidad/1336131772_277981.html>. Acesso em: set. 2012.

GOMES, Wilson. Jornalismo, fatos e interesses. Ensaios de teoria do jornalismo. Série Jornalismo a Rigor, vol. 1. Florianópolis: Insular, 2009.

GOSÁLVEZ, Patricia. Um mercado de felicidade. In: El País, El Viajero, 19 abr. 2012. Disponível em: $<$ http://elviajero.elpais.com/elviajero/2012/04/19/actualidad/1334828044_850215.html>. Acesso em: set. 2012.

GROTH, Otto. O poder cultural desconhecido. Fundamentos das Ciências dos Jornais. Trad. Liriam Sponholz. Petrópolis: Vozes, 2011.

ISER, Wolfgang. O ato de leitura. Uma teoría do efeito estético, vol. 1. São Paulo: Ed. 34, 1996.

JAKOBSON, Roman. Linguística e comunicação. São Paulo: Cultrix, 1995.

LAGE, Nilson. A estrutura da notícia. São Paulo: Ática, 1993.

LEITÃO, Miriam. França: porta aberta para conciliar corte e crescimento. In: O Globo, Rio de Janeiro, 7 maio 2012. Disponível em: <http://oglobo.globo.com/economia/miriam/>. Acesso em: set. 2012.

MACHADO, Irene. Comunicação de sínteses em perspectiva semiótico-evolutiva: modelização de linguagens, de formatos, do signo informático, de temporalidades. In: Revista Fronteiras, Unisinos, 
maio/agosto de 2010, p. 95-104. Disponível em: <http://www.fronteiras.unisinos.br/pdf/90.pdf>. Acesso em: jul. 2012.

MARCUSCHI, Luiz Antônio. Gêneros textuais: definição e funcionalidade. In: DIONISIO, A.; MACHADO, A.; BEZERRA, M. (Org.). Gêneros textuais \& ensino. Rio de Janeiro: Lucerna, 2002, p. 19-36. Disponível em: <http://pt.scribd.com/doc/61404180/Generos-textuais-definicao-efuncionalidade-Luiz-Antonio-Marcuschi>. Acesso em: jul. 2012.

MARQUES DE MELO, José. A opinião no jornalismo brasileiro. 2 ed. revista. Petrópolis: Vozes, 1994.

MCLUHAN, Marshall. Os meios de comunicação como extensões do homem. Trad. Décio Pignatari. 4 ed. São Paulo: Cultrix, 1974.

MEDITSCH, Eduardo. O jornalismo é uma forma de conhecimento? Beira Interior, Portugal: set. 1997. Disponível em: <http://www.bocc.ubi.pt/pag/meditsch-eduardo-jornalismo-conhecimento. pdf>. Acesso em: jul. 2012.

MIRANDA, André. "Homens de Preto 3" terá viagem no tempo e Josh Brolin no elenco. In: O Globo, Rio de Janeiro, 7 maio 2012. Disponível em: <http://oglobo.globo.com/cultura/homens-de-preto-3tera-viagem-no-tempo-josh-brolin-no-elenco-4825571>. Acesso em: set. 2012.

RODRIGUES, A. D. O acontecimento. In: TRAQUINA, Nelson (Org.). Jornalismo: questões, teorias e "estórias". Lisboa: Vega, 1999.

SCHUDSON, Michael. News and Democratic Society: Past, Present, and Future. In: The Hedgehog Review, Institute for Advanced Studies in Culture, Summer 2008. Disponível em: <http://www.iascculture.org/eNews/2009_10/Schudson_LO.pdf>. Acesso em: jul. 2012.

SEIXAS, Lia. Gêneros jornalísticos: partindo do discurso para chegar à finalidade. Artigo apresentado no $32^{\circ}$ Congresso Brasileiro de Ciências da Comunicação, Curitiba, 2009.

SEIXAS, Lia. Redefinindo os gêneros jornalísticos. Proposta de novos critérios de classificação. Portugal: LabCom Books, 2009. (Coleção Estudos de Comunicação). Disponível em: <http://www. livroslabcom.ubi.pt/sinopse/seixas-classificacao-2009.html>. Acesso em:

SOUSA, Jorge Pedro. Introdução à análise do discurso jornalístico impresso. Um guia para estudantes de graduação. Florianópolis: Letras Contemporâneas, 2004.

TUCHMAN, Gaye. Making News. A study in the construction of reality. New York: Free Press, 1980.

Artigo recebido em julho e aprovado em dezembro de 2012. 